\title{
CARACTERIZAÇÃO MORFOLÓGICADE FRUTOS E SEMENTES DE CATAIA (Drimys brasiliensis MIERS. - WINTERACEAE) ${ }^{1}$
}

\author{
DANIELACLEIDEAZEVEDO DEABREU ${ }^{2}$, YOSHIKO SAITO KUNIYOSHI ${ }^{3}$, ANTONIO CARLOSDE SOUZAMEDEIROS $^{4}$, \\ ANTONIOCARLOSNOGUEIRA ${ }^{5}$
}

\begin{abstract}
RESUMO - Este trabalho teve como objetivo caracterizar morfologicamente as estruturas externas e internas dos frutos e das sementes de cataia (Drimys brasiliensis Miers.). Para a descrição dos frutos foram observados detalhes externos e internos do pericarpo, referentes à textura, consistência, pilosidade, brilho, forma, número de sementes por fruto e deiscência. Para as sementes foram analisadas as seguintes variáveis externas: dimensões, cor, textura, consistência, forma, posição do hilo e da micrópila. Para as características internas, verificou-se a presença ou ausência de endosperma, o tipo, a forma, a cor, o desenvolvimento embrionário e posição dos cotilédones, do eixo-hipocótilo-radícula e da plúmula. Durante o desenvolvimento embrionário, foram encontrados embriões que variaram de acordo com a diferenciação celular, evidenciando seus aspectos morfológicos, nos estágios de coração, torpedo e maduro. Os frutos de $D$. brasiliensis são múltiplos, livres, constituídos por cinco frutíolos, bagas, indeiscentes e polispérmicos. As sementes são reniformes e têm grande quantidade de endosperma, e apresentam dormência por imaturidade embrionária.
\end{abstract}

Termos para indexação: espécie florestal, morfologia de frutos e sementes, desenvolvimento embrionário.

\section{MORPHOLOGICAL CHARACTERIZATION OF FRUITS ANDS SEEDS OF Drimys brasiliensis Miers. - (WINTERACEAE)}

\begin{abstract}
The aim of this research was to characterize morphologically internal and external structures of Drimys brasiliensis Miers fruits and seeds. In order to describe the fruits, internal and external details related to texture, consistency, pilosity, brightness, shape and number of seeds per fruit were observed. Shedding was observed as well. Some external aspects of the seeds were analyzed including size, color, texture, consistency, shape, hilum and micropyle position. The following internal characteristics were observed the presence or absence of endosperm and cotyledon, embryo axes and plumule type, shape and color. The heart, torpedo and mature stages were identified during embryo development. The fruits of D. brasiliensis are multiple, free, constituted by five little fruits, indehiscence and polispermic. The seeds are kedney form and they have great amount of endosperm, and they present dormancy for embryonic immaturity
\end{abstract}

Index terms: forest specie, fruits and seeds morphology, embrionary development

\section{INTRODUÇÃO}

Drimys brasiliensis Miers. é conhecida como cascad'anta, cataia, copororoca-picante, carne-de-anta, melambo, paratudo, pau-para-tudo, casca-de-anta, canela-amarga, paucasca-de-anta, cataeira e em tupi-guarani como caá-tuya, que

\footnotetext{
${ }^{1}$ Submetido em 02/03/2004 Aceito para publicação em 27/04/2005 Parte da Dissertação de Mestrado do primeiro autor.

${ }^{2}$ Bióloga, MSc. em Ciências Florestais da UFPR, Bolsista CAPES, CuritibaPR. daniela@cnpf.embrapa.br

${ }^{3}$ Naturalista, Dr ${ }^{\text {a }}$. Depto. de Ciências Florestais da UFPR, Curitiba-PR. yoshiko@floresta.ufpr.br
}

significa árvore-para-velho (Schultz, 1975; Barroso, 1978b; Lorenzi, 1992; Longhi, 1995).

O gênero Drimys é o de maior área de distribuição geográfica da família Winteraceae, contando com representantes desde as Filipinas e Bornéu, até a Tasmânia. No continente americano, sua área de ocorrência estende-se

\footnotetext{
${ }^{4}$ Eng. Agrônomo, PhD, Pesquisador da Embrapa-Florestas, Colombo- PR. medeiros@cnpf.embrapa.br

${ }^{5}$ Eng. Florestal, Dr., Depto. de Ciências Florestais da UFPR, Curitiba-PR. nogueira@floresta.ufpr.br
} 
desde o extremo sul da Argentina e Chile até o México (Marchiori, 1997). Segundo Joly (1985), o gênero é restrito às regiões de climas temperados. Em território brasileiro, encontra-se desde a Bahia até o Rio Grande do Sul (Backes e Nardino, 1999).

Essa espécie é heliófila, perenifólia e seletiva hidrófila, ocorre em florestas riparias e pinhais do planalto sul-brasileiro (Marchiori, 1997) e na Floresta Estacional Semidecidual (Figliolia e Piña-Rodrigues, 1995).

Sua madeira é única, dentre as angiospermas dicotiledôneas da flora brasileira, com ausência de elementos vasculares. A estrutura anatômica compõe-se inteiramente de traqueídeos longitudinais, parênquima axial, raios e com grandes pontoações. Estes, por serem muito conspícuos, contribuem para a identificação dendrológica da espécie, quando se examinam os tecidos internos da casca ou da madeira, comprovando a primitividade desta família da ordem Magnoliales, à semelhança dos caracteres morfológicos externos e reprodutivos (Marchiori, 1997). As espécies desta ordem têm sido consideradas como as angiospermas viventes mais primitivas, daí concentrarem nelas, pesquisas a respeito da evolução do carpelo, bem como de outras partes florais (Barroso et al., 1999).

O conhecimento das estruturas morfológicas do fruto, da semente e das plântulas florestais é importante para diversos fins como: nos laboratórios de análise de sementes, na identificação e diferenciação de espécies, no reconhecimento da planta no campo, na taxonomia e na silvicultura, havendo necessidade de estímulos a esses estudos básicos (Amorim, 1996). Estas estruturas podem fornecer indicações sobre armazenamento, viabilidade e métodos de semeadura (Kuniyoshi, 1983). Da mesma forma, contribuem para uma correta interpretação dos testes germinativos e à realização de trabalhos científicos (Araújo e Matos, 1991). Auxilia na compreensão da dinâmica de populações vegetais, bem como, o reconhecimento do estágio sucessional em que a floresta se encontra (Oliveira, 1993; Donadio e Demattê, 2000).

As sementes, algumas vezes, têm características básicas que permitem a identificação da família ou até mesmo do gênero, espécie ou variedade; mas freqüentemente, são apenas um elemento a mais na cadeia de caracteres que servem para identificar uma planta (Barroso, 1978a). Entretanto, na Botânica Sistemática, os caracteres da planta adulta são os mais utilizados, mas, no entanto as características reprodutivas das plantas são pouco utilizadas, talvez pela limitação de dados e falta de tradição (Donadio e Demattê, 2000).

Vários estudos sobre a morfologia de frutos e sementes têm sido desenvolvidos, muitos deles de forma parcial e essencialmente limitada à descrição de suas formas mais gerais. Contudo, alguns autores desenvolveram estudos com grande diversidade de espécies florestais que permitem informações amplas e complexas sobre elas. Como exemplo, cita-se Kuniyoshi (1983), que descreveu 25 espécies arbóreas da Floresta Ombrófila Mista (Floresta com Araucária), fornecendo características dos frutos, das sementes e do desenvolvimento das plântulas. Barroso et al. (1999) analisou e descreveu a morfologia externa e interna de frutos e sementes de várias famílias de dicotiledôneas. Amorim (1996) caracterizou e descreveu a morfologia de frutos, sementes, germinação, plântulas e mudas de espécies florestais da região de Lavras, no Estado de Minas Gerais. Beltrati (1973) ilustrou e descreveu a morfologia das sementes e a germinação de 18 espécies de Eucalyptus. Feliciano (1989) estudou a germinação de sementes e o desenvolvimento da muda, acompanhado de descrições morfológicas de 10 espécies arbóreas do semiárido nordestino. Silva et al. (1995) estudaram a morfologia do fruto, da semente e o desenvolvimento de plântulas, descrevendo plântulas normais e anormais de Luetzelburgia auriculata Duck.e Pterogyne nitens Tul.. Amorim et al. (1997) observaram as características internas e externas dos frutos e sementes de Trema micrantha (L.) Blum., concluindo que estas características contribuem para o seu reconhecimento no campo. O reconhecimento e a identificação dessas características morfológicas externas e internas é uma importante ferramenta para a compreensão e descrição do processo germinativo. Paoli (1992) forneceu bases para o reconhecimento das fases iniciais da germinação de Luehea grandiflora Mart.. Outros trabalhos sobre a morfologia de frutos e sementes de Cryptocaria moschata Nees \& Martius, Endlicheria paniculata (Sprengel) MacBride e Ocotea catharinensis Mez. foram realizados por Moraes e Paoli (1996). Ferreira et al. (1998) caracterizaram morfologicamente o fruto, a plântula e a muda de Dipteryx alata Vogel.

No trabalho de morfologia envolvendo frutos e sementes de Drimys brasiliensis Miers, estudos realizados por Barroso et al. (1999), os frutos foram classificados como bagas indeiscentes, de coloração vermelho-escura, passando para pretas quando maduras, com o fruto formado por cinco frutíolos carnosos. Longhi (1995) observou que quatro ou cinco das sementes de $D$. brasiliensis são férteis e as restantes são abortadas. As sementes são reniformes, pequenas e curvas, de coloração preta, de 2-4mm (Marchiori, 1997; Longhi, 1995) e Barroso et al. (1999) citam que as sementes têm endosperma carnoso e embrião diminuto. 
Este trabalho teve por objetivo caracterizar morfologicamente as estruturas externas e internas dos frutos e das sementes de Drimys brasiliensis Miers.

\section{MATERIALE MÉTODOS}

Os frutos de Drimys brasiliensis Miers. foram coletados em maio de 2001, de doze matrizes no município de Campina Grande do Sul - PR. A região é caracterizada por clima tipo Cfb (Köepen), uma altitude de 918m, a 2529'S e 4951'W, com precipitação média anual de $1458 \mathrm{~mm}$. Amostras de galhos com flores de $D$. brasiliensis foram herborizadas e secadas em estufa elétrica. As exsicatas se encontram no Herbário do curso de Engenharia Florestal da Universidade Federal do Paraná, acondicionadas em latas de zinco e registradas sob o n. ${ }^{\circ}$ EFC 4643. A caracterização morfológica dos frutos e das sementes de $D$. brasiliensis foi realizada no Laboratório de Sementes Florestais do Departamento de Ciências Florestais da Universidade Federal do Paraná.

Para descrever e ilustrar morfologicamente os frutos e as sementes foram utilizados 100 unidades, retiradas aleatoriamente. Os frutos foram macerados e despolpados em água corrente para a obtenção das sementes. Em seguida, as sementes foram submetidas ao tratamento pré-germinativo de estratificação em areia em diferentes épocas: 30, 60 e 90 dias em casa de vegetação.

As observações foram realizadas com lupa de mesa estereoscópica e a olho nu. Foram anotadas as medidas de comprimento, largura e espessura, com auxilio de paquímetro digital, expressas em milímetro. Considerou-se o comprimento, tanto dos frutos como das sementes, a distância entre a base e o ápice; para a largura, o lado mais largo e para a espessura, o lado mais estreito. Para a descrição dos frutos foram observados detalhes externos e internos do pericarpo, referentes à textura, consistência, pilosidade, brilho, forma, número de sementes por fruto e deiscência.

Foram realizados cortes transversais e longitudinais com lâminas de bisturi nas sementes. As seguintes variáveis das sementes foram analisadas: externas: dimensões, coloração, textura, consistência, forma, posição do hilo e da micrópila; internas: presença ou ausência de endosperma, o tipo, a forma e a coloração.

O procedimento tecnológico para a morfologia foi baseado nos trabalhos de Barroso (1978a), Kuniyoshi (1983), Feliciano (1989), Beltrati (1992), Chaves (1994), Amorim (1996), Barroso et al. (1999) e Vidal e Vidal (2000).

Todo o material para a morfologia foi conservado em álcool etílico a 70\% e as ilustrações foram feitas manualmente, de material bem desenvolvido e representativo de cada fase. Na classificação dos embriões foram utilizadas sementes recém coletadas e estratificadas, correspondendo às seguintes épocas: sem estratificação, 60 e 90 dias de estratificação. Para 30 dias de estratificação, não foi possível determinar os estágios de desenvolvimento, devido ao número insuficiente de sementes. Para a porcentagem de embriões, nos diferentes estágios de desenvolvimento, foram utilizadas 100 sementes de cada época de estratificação. Estas foram colocadas em lâminas e examinadas quanto à forma e ao tamanho do embrião, com auxílio de uma ocular micrométrica, em microscópio estereoscópico Bausch \& Lomb (3X), sendo as medidas transformadas em milímetros. A avaliação quanto à forma baseou-se nos trabalhos de Heuser (1990) e Catapan (1998). Para as medidas de tamanho e forma foram utilizados 30 embriões. As fotografias dos embriões foram obtidas em microscópico com aumento de 3X.

\section{RESULTADOS E DISCUSSÃO}

a) Caracterização morfológica de frutos e sementes

Frutos: múltiplos, livres, constituídos por cinco frutíolos, cada frutíolo é denominado de baga, indeiscente, carnáceo e polispérmico. As bagas ficam dispostas no ápice do receptáculo curto, de acordo com a classificação de Barroso et al. (1999). Epicarpo glabro e sem brilho. As bagas são de coloração roxa-escura, quando maduros (Figura 1A e 2A-C). Mesocarpo de consistência sucosa que quando macerados, liberam uma substância aromática de coloração vinho. Cada baga com no máximo nove e no mínimo duas sementes. O número médio de sementes encontradas por baga foi de seis sementes, com desvio padrão de 1,57 e coeficiente de variação de $26,01 \%$.

Semente: reniforme, preta, brilhante, estenospérmica e monocrômica (Figura 1B e 2D). Cada semente é presa por um funículo curto. Hilo e micrópila não são visíveis a olho nu, localizados na região basal, junto ao embrião rudimentar, uma massa esférica de células indiferenciadas, que se confunde com o endosperma oleaginoso, de coloração translúcida. O embrião ocupa apenas uma pequena parte no interior do tecido nutritivo. Durante o desenvolvimento, o comprimento varia de 0,36-6mm (Tabela 1) e, de acordo com a diferenciação celular, pode-se apresentar nos estágios de globular, coração, torpedo e maduro. O embrião no estágio globular caracterizase por não apresentar a diferenciação dos cotilédones. O estágio de coração é caracterizado pelo início da formação dos cotilédones. No estágio torpedo, os cotilédones e o eixo embrionário estão mais alongados e, na fase mais avançada 

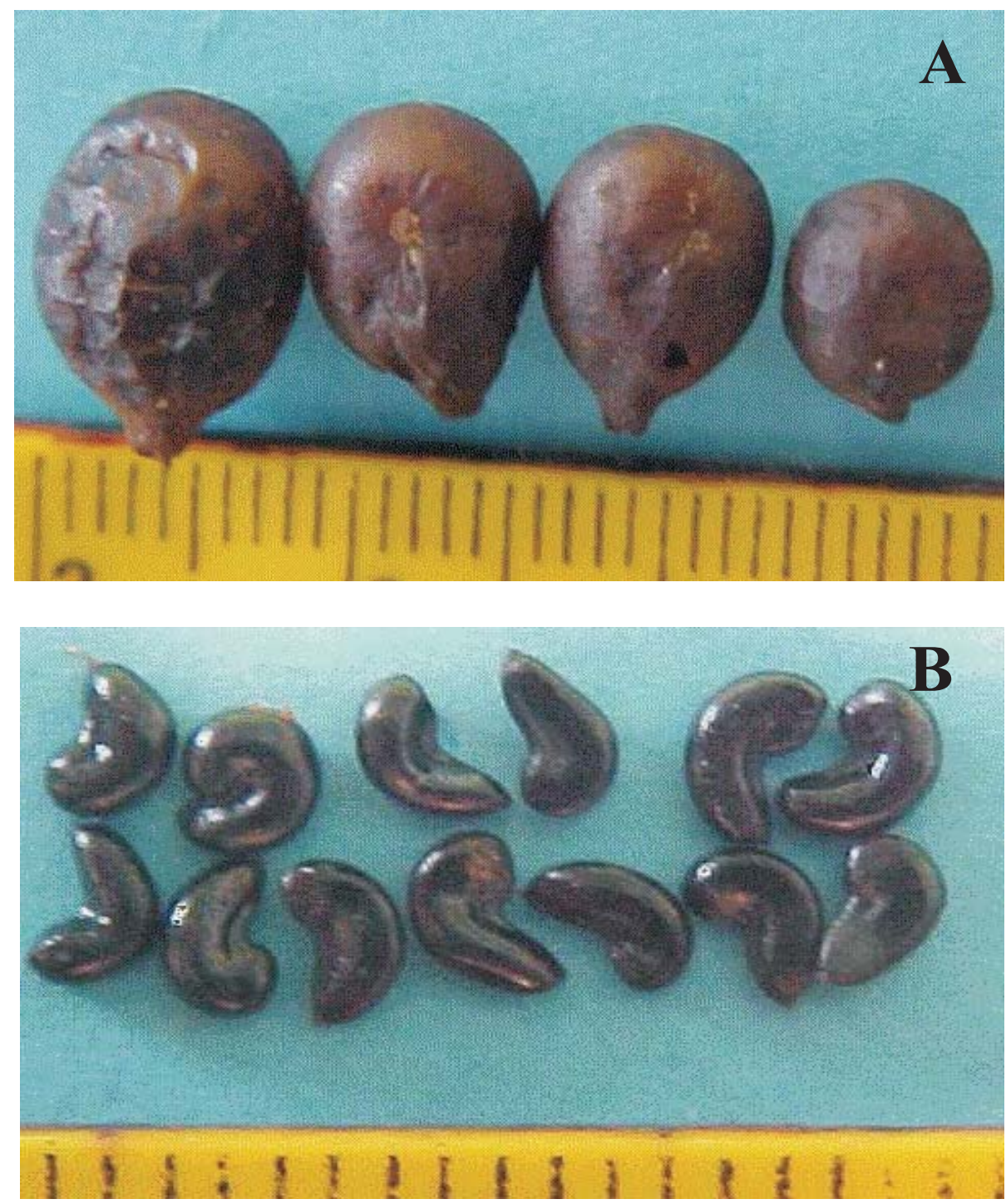

FIGURA 1. Frutos e sementes de Drimys brasiliensis Miers: A-frutos; B - sementes.

do desenvolvimento, a forma do embrião está bem definida, com cotilédones bem formados (Figura 2 F-I).

Nas Tabelas 2 e 3, encontram-se as dimensões do comprimento, largura e espessura do fruto e da semente, respectivamente.

b) Forma dos embriões: encontra-se na Figura 3 a caracterização morfológica de embriões de D. brasiliensis, na forma globular, coração, torpedo e maduro, avaliados em sementes sem estratificação, com 60 e 90 dias de estratificação. não foram avaliadas as diferentes fases de desenvolvimento embrionário, com 30 dias de estratificação, devido ao número insuficiente de sementes.

c) Diferentes fases de desenvolvimento: observou- se que na amostragem de sementes sem estratificação 6\% dos embriões apresentavam a forma globular e $94 \%$ a de coração. Com 60 dias de estratificação, $9 \%$ dos embriões apresentaram a forma de coração, $8 \%$ a de torpedo e $83 \%$ estavam maduros. Com 90 dias 14\% na de coração, 15\% na de torpedo e $71 \%$ estavam maduros. Nota-se que ocorreu um incremento na porcentagem de embriões com forma de maduro, nos períodos de 60 e 90 dias de estratificação, quando comparados com as sementes sem estratificação, que apresentavam com maior porcentagem de embriões com forma de coração.

A forma dos embriões é utilizada para determinar os estágios de desenvolvimento dos mesmos. O desenvolvimento 
TABELA 1. Classificação do tamanho dos embriões de Drimys brasiliensis Miers.

\begin{tabular}{cccccc}
\hline Forma do embrião $(\mathrm{mm})$ & Média & Máximo & Mínimo & Desvio padrão & Coeficiente de variação \\
\hline Coração & 0,42 & 0,51 & 0,36 & 0,043 & 10,43 \\
Torpedo & 0,83 & 1,08 & 0,57 & 0,155 & 18,74 \\
Maduro & 4,06 & 6,00 & 2,00 & 1,209 & 293,73 \\
\hline
\end{tabular}

TABELA 2. Dimensões do fruto de Drimys brasiliensis Miers.

\begin{tabular}{lrrccc}
\hline \multicolumn{1}{c}{ Dimensões $(\mathrm{mm})$} & Média & Máximo & Mínimo & Desvio padrão & Coeficiente de variação \\
\hline Comprimento & 9,86 & 12,49 & 6,45 & 1,21 & 12,32 \\
Largura & 7,07 & 9,59 & 5,20 & 0,79 & 11,17 \\
Espessura & 6,45 & 9,47 & 4,85 & 0,86 & 12,81 \\
\hline
\end{tabular}

TABELA3. Dimensões da semente de Drimys brasiliensis Miers.

\begin{tabular}{lccccc}
\hline Dimensões $(\mathrm{mm})$ & Média & Máximo & Mínimo & Desvio padrão & Coeficiente de variação \\
\hline Comprimento & 3,17 & 4,13 & 1,88 & 0,46 & 14,49 \\
Largura & 1,72 & 3,01 & 1,09 & 0,37 & 21,77 \\
Espessura & 1,24 & 1,80 & 0,83 & 0,16 & 13,03 \\
\hline
\end{tabular}

de embriões inicia-se pela formação de uma massa de células de forma globular, passando para a forma de coração e, seqüencialmente pelos estágios de torpedo e maduro, quando então, é considerado apto para germinar (Cunha, 1990).

Estas fases do desenvolvimento embrionário estão diretamente relacionadas com o tamanho do embrião. A maior parte dos trabalhos referentes à classificação dos embriões nas várias fases, foi realizada para pirênios de Ilex paraguariensis A. St.-Hil. por Kuniyoshi (1983); Niklas (1987); Heuser (1990) e Catapan (1998).

Para as sementes de Drimys brasiliensis, a classificação das fases do desenvolvimento embrionário e suas respectivas medidas, ainda não haviam sido relatadas. Dessa forma, as mesmas foram classificadas quanto à forma do embrião (coração, torpedo e maduro), nas diferentes fases do desenvolvimento, conforme apresentado na Tabela 3 e nas Figuras 3A-C.

Para os embriões na forma globular, não foram efetuadas as medidas do tamanho, o que pode ser justifica pela baixa ocorrência desta fase, em sementes não estratificadas e pela ausência desse estágio em sementes com 60 e 90 dias de estratificação, impossibilitando a amostragem no momento da avaliação.

Analisando os resultados da Tabela 3 e a forma dos embriões nas diferentes fases de desenvolvimento (Figuras 3A-C), nota-se que houve mudança morfológica e aumento de tamanho dos embriões. Esse aumento está relacionado com as fases do embrião, sendo que a classificação apresenta diferenças quanto às medidas de comprimento (Catapan,
1998). Considerando o tamanho dos embriões, sugere-se que essas diferenças também ocorram entre as diferentes espécies. Para Ilex paraguariensis A. St.-Hil., as medidas dos estágios de coração, torpedo e maduro, encontrados por Cunha (1990), foram de $(0,20-0,45 \mathrm{~mm}),(0,45-0,70 \mathrm{~mm})$ e $(0,70-1,00 \mathrm{~mm})$, respectivamente. Estes valores demonstram que os embriões de $D$. brasiliensis são maiores, quando comparados com embriões de Ilex paraguariensis A. St.-Hil.

Pelas Figuras 2 e 3, observa-se que não há sincronia no desenvolvimento morfológico entre fruto e embrião, isto é, quando os frutos estão maduros, os embriões ainda se encontram na fase rudimentar no momento da dispersão. Portanto, os embriões de $D$. brasiliensis são rudimentares e necessitam de um período adicional para completar seu desenvolvimento antes de tornarem-se aptos para germinar. Essa constatação concorda com Catapan (1998), que cita a ocorrência de diferentes formas de embriões nas sementes e o conhecimento do seu desenvolvimento contribui para a identificação das causas de dormência de algumas espécies.

\section{CONCLUSÕES}

Os frutos de Drimys brasiliensis são múltiplos, livres, constituídos por cinco frutíolos, bagas, indeiscentes e polispérmicos.

As sementes de $D$. brasiliensis são reniformes, têm grande quantidade de endosperma e apresentam dormência por imaturidade embrionária. 


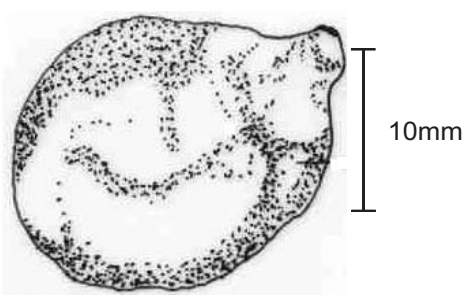

A

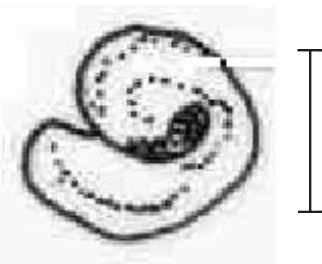

D

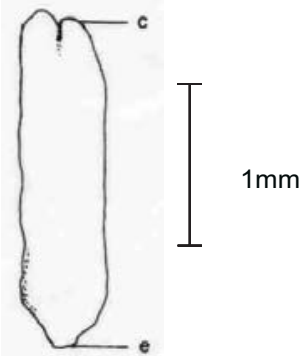

G

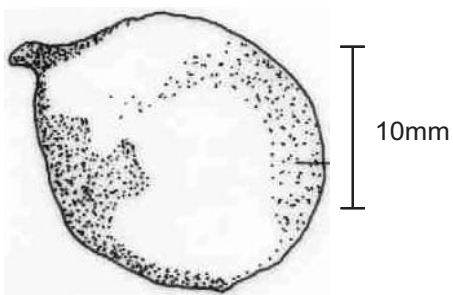

B

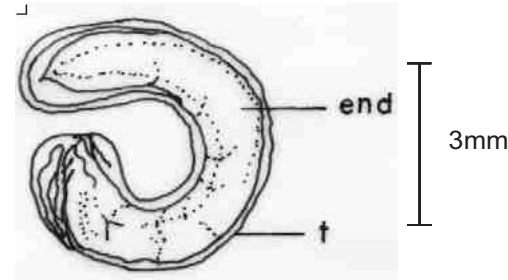

$\mathrm{E}$

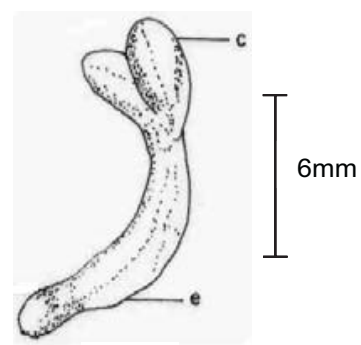

$\mathrm{H}$

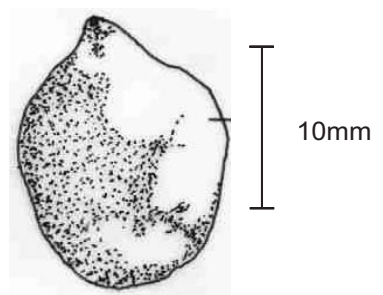

C

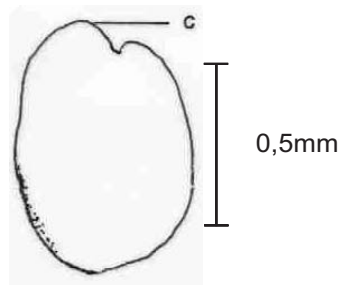

$\mathrm{F}$

FIGURA2. Drimys brasiliensis Miers.: A-B-C - fruto; D - semente; E - corte longitudinal da semente; $F$ - embrião no estágio de coração; G-embrião no estágio de torpedo; H-I-embrião maduro Legenda: c -cotilédone; e-eixo-hipocótilo-radícula; end-endosperma; $t$-tegumento.

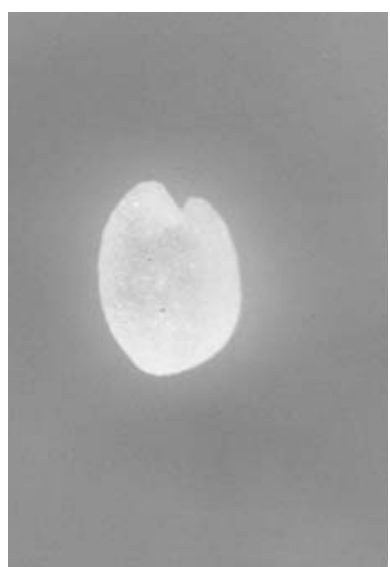

A

$0,5 \mathrm{~mm}$

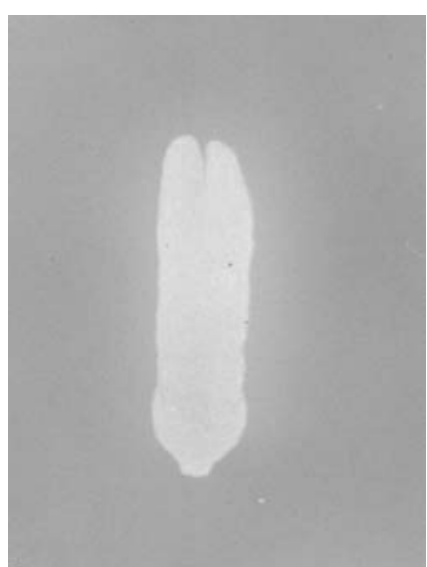

B

$1 \mathrm{~mm}$

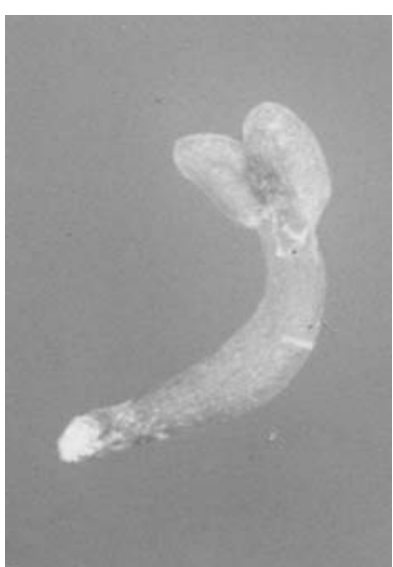

$\mathrm{C}$

$6 \mathrm{~mm}$

FIGURA 3. Caracterização morfológica dos embriões de Drimys brasiliensis Miers. em diferentes fases de desenvolvimento: Acoração; B - torpedo e C - maduro. 


\section{AGRADECIMENTOS}

Os autores agradecem ao Centro Nacional de Pesquisas Florestais (CNPF) - Embrapa-Florestas por todo apoio e à concessão da infra-estrutura laboratorial na execução deste trabalho. À Universidade Federal do Paraná, pela realização do curso e à CAPES, pela concessão da bolsa de estudos e ao prof. Dr. Iedo Alquini do Departamento de Botânica da UFPR, pelo auxílio e presteza na confecção das fotografias dos embriões.

\section{REFERÊNCIAS}

AMORIM, I.L. Morfologia de frutos, sementes, germinação, plântulas e mudas de espécies florestais da região de Lavras - MG. 1996. 127f. Dissertação (Mestrado em Engenharia Florestal) - Departamento de Silvicultura, Universidade Federal de Lavras. Lavras, 1996

AMORIM, I.L.; DAVIDE, A.C.; CHAVES, M.M.F. Morfologia do fruto e da semente, e germinação da semente de Trema micrantha (L.) Blum. Revista Cerne, Lavras, v.3, n.1, p.129-142, 1997.

BACKES, A.; NARDINO, M. Nomes populares e científicos de plantas do Rio Grande do Sul. São Leopoldo: UNISINOS, 1999. 202p.

BARROSO, G.M. Curso de identificação de sementes. Pelotas: UFPel, 1978a. 36p.

BARROSO, G.M. Sistemática de angiospermas do Brasil. São Paulo: EDUSP, 1978b. v.1, 255p.

BARROSO, G.M.; MORIM, M.P.; PEIXOTO, A.L.; ICHASO, C.L.F. Frutos e sementes: morfologia aplicada à sistemática de dicotiledôneas. Viçosa: UFV, 1999. 443p.

BELTRATI, C.M. Morfologia das sementes e de sua germinação, em dezoito espécies de Eucalyptus. 1973. $236 \mathrm{f}$. Dissertação (Mestrado em Ciências) - Faculdade de Filosofia e Letras de Rio Claro. Rio Claro, 1973.

BELTRATI, C.M.. Morfologia e anatomia de sementes. Rio Claro: UNESP, 1992. 108 p. Apostila do Curso de PósGraduação.

CHAVES, M.M.F. Descrição morfológica de sementes, de plântulas e de mudas de 10 espécies arbóreas pioneiras, na microrregião de Viçosa - MG. 1994. 108p. Dissertação (Mestrado em Ciências Florestais) - Departamento de Engenharia Florestal, Universidade Federal de Viçosa. Viçosa, 1994.

CATAPAN, M.I.S. Influência da temperatura, substrato e luz na germinação de sementes de Ilex paraguariensis St.Hil. 1998. 97f. Dissertação (Mestrado em Ciências Florestais) - Departamento de Engenharia Florestal, Universidade Federal do Paraná. Curitiba, 1998.

CUNHA, G.G. Cultura de embriões de erva-mate (Ilex paraguariensis St.Hil.) “in vitro” 1990. 51f. Dissertação
(Mestrado em Botânica) Departamento de Ciências Biológicas, Universidade Federal do Rio Grande do Sul, Porto Alegre, 1989.

DONADIO, N.M.M.; DEMATTÊ, M.E.S.P. Morfologia de frutos, sementes, e plântulas de canafístula (Peltophorum dubium (Spreng.) Taub.) e jacarandá-da-Bahia (Dalbergia nigra (Vell.) Fr. All. ex Benth.) - Fabaceae. Revista Brasileira de Sementes, Brasília, v.22, n.1, p.64-73, 2000.

FELICIANO, A.L.P. Estudos da germinação de sementes e desenvolvimento da muda, acompanhamento de descrições morfológicas de 10 espécies arbóreas ocorrentes no semiárido nordestino 1989. 114f. Dissertação (Mestrado em Engenharia Florestal) - Universidade Federal de Viçosa, Viçosa, 1989.

FERREIRA, R.A.; BOTELHO, S.A.; DAVIDE, A.C.; MALAVASI, M.M. Caracterização morfológica de fruto, semente, plântula e muda de Dipteryx alata Vogel - baru (Leguminosae Papilionoideae). Revista Cerne, Lavras, v.14, n.1, p.7-87, 1998

FIGLIOLIA, M.B.; PIÑA-RODRIGUES, F.C.M. Manejo de sementes de espécies arbóreas. IF. Série registros, São Paulo, n.14, p.1-56, 1995.

HEUSER, E.D. Ilex paraguariensis St.Hil. Endosperma e embrião durante a embriogênese tardia. 1990. $76 \mathrm{f}$. Dissertação (Mestrado em Botânica) - Departamento de Ciências Biológicas, Universidade Federal do Rio Grande do Sul, Porto Alegre, 1990.

JOLY, A.B. Botânica: introdução à taxonomia vegetal. 12.ed. São Paulo: Nacional, 1985. 777p.

KUNIYOSHI, Y.S. Morfologia da semente e da germinação de 25 espécies arbóreas de uma floresta com araucária. 1983. 233f.. Dissertação (Mestrado em Ciências Florestais) - Departamento de Engenharia Florestal, Universidade Federal do Paraná, Curitiba, 1983

LONGHI, R.A. Livro das árvores e arvoretas do sul. Porto Alegre: L \& PM, 1995. 176p.

LORENZI, H. Árvores brasileiras: manual de identificação e cultivo de plantas arbóreas nativas do Brasil. Nova Odessa: Plantarum, 1992. 368p.

MARCHIORI, J.N.C. Dendrologia das angiospermas: das magnoliáceas às flacurtiáceas. Santa Maria: UFSM, 1997. 271p.

MORAES, P.L.R.; PAOLI, A.A.S. Morfologia de frutos e sementes de Cryptocaria moschata Nees \& Martius Endlicheria paniculata (Sprengel) MacBride e Ocotea catharinensis Mez (Lauraceae). Revista Brasileira de Sementes, Brasília, v.18, n.1, p.17-27, 1996.

NIKLAS, C.O. Estudios embriológicos y citológicos em la yerba mate - Ilex paraguariensis (Aquifoliaceae). Bonplandia, Corrientes, v.6, n.1, p.45-56, 1987.

OLIVEIRA, E.C. Morfologia de plântulas florestais. In: AGUIAR, I.B.; PIÑA-RODRIGUES, F.C.M. Sementes Florestais Tropicais, Brasília: ABRATES, 1993. p.175-214. 
PAOLI, A.A.S. Estudo morfo-anatômico do desenvolvimento de frutos, sementes e plântulas de Luehea grandiflora Mart. \& Zucc. (Tiliaceae). Revista Brasileira de Sementes Florestais, Brasília, v.14, n.1, p.21-29, 1992.

SILVA, L.M.M.; MATOS, V.P.; PEREIRA, D.D.; LIMA, A.A. Morfologia de frutos, sementes e plântulas de Luetzelburgia auriculata Duck. (pau-serrote) e Pterogyne nitens Tul. (madeira-nova-do-brejo) Leguminosae. Revista Brasileira de Sementes, Brasília, v.17, n.2, p.154-159, 1995.

SCHULTZ, R.A. Os nomes científicos e populares das plantas do Rio Grande do Sul. Porto Alegre. PUC, 1975. 164p.

VIDAL, W.N.; VIDAL, M.R.R. Botânica: organografia. 4.ed. Viçosa: UFV, 2000. 114p.

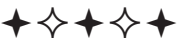

